\title{
RESEARCH
}

Open Access

\section{Orthodontic bonding procedures significantly influence biofilm composition}

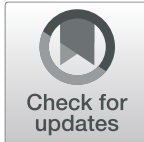

Da-Mi Jeon ${ }^{1}$, Jung-Sub An², Bum-Soon Lim³ and Sug-Joon Ahn ${ }^{4^{*}}$ (D)

\begin{abstract}
Background: Because changes in surface properties affect bacterial adhesion, orthodontic bonding procedures may significantly influence biofilm formation and composition around orthodontic appliances. However, most studies used a mono-species biofilm model under static conditions, which does not simulate the intraoral environment and complex interactions of oral microflora because the oral cavity is a diverse and changeable environment. In this study, a multi-species biofilm model was used under dynamic culture conditions to assess the effects of the orthodontic bonding procedure on biofilm formation and compositional changes in two main oral pathogens, Streptococcus mutans and Porphyromonas gingivalis.

Methods: Four specimens were prepared with bovine incisors and bonding adhesive: untreated enamel surface (BI), enamel surface etched with 37\% phosphoric acid (ET), primed enamel surface after etching (PR), and adhesive surface (AD). Surface roughness (SR), surface wettability (SW), and surface texture were evaluated. A multi-species biofilm was developed on each surface and adhesion amounts of Streptococcus mutans, Porphyromonas gingivalis, and total bacteria were analyzed at day 1 and day 4 using real-time polymerase chain reaction. After determining the differences in biofilm formation, SR, and SW between the four surfaces, relationships between bacteria levels and surface properties were analyzed.
\end{abstract}

Results: The order of $\mathrm{SR}$ was $\mathrm{AD}<\mathrm{PR}<\mathrm{BI}<\mathrm{ET}$, as $\mathrm{BI}$ and $\mathrm{ET}$ showed more irregular surface texture than $\mathrm{PR}$ and $A D$. For SW, ET had the greatest value followed by $P R, B I$, and $A D$. S. mutans and $P$. gingivalis showed greater adhesion to $\mathrm{BI}$ and $\mathrm{ET}$ with rougher and more wettable surfaces than to AD with smoother and less wettable surfaces. The adhesion of total bacteria and $S$. mutans significantly increased over time, but the amount of $P$. gingivalis decreased. The adhesion amounts of all bacteria were positively correlated with SR and SW, irrespective of incubation time.

Conclusions: Within the limitations of this study, changes in SR and SW associated with orthodontic bonding had significant effects on biofilm formation and composition of $S$. mutans and $P$. gingivalis.

Keywords: Orthodontic bonding, Surface roughness, Surface wettability, Biofilm, Composition

\footnotetext{
* Correspondence: titoo@snu.ac.kr

${ }^{4}$ Dental Research Institute and Department of Orthodontics, Seoul National

University School of Dentistry, 101 Daehakro, Jongro-Gu, Seoul 03080,

Republic of Korea

Full list of author information is available at the end of the article
}

\section{Springer Open}

() The Author(s). 2020 Open Access This article is licensed under a Creative Commons Attribution 4.0 International License, which permits use, sharing, adaptation, distribution and reproduction in any medium or format, as long as you give appropriate credit to the original author(s) and the source, provide a link to the Creative Commons licence, and indicate if changes were made. The images or other third party material in this article are included in the article's Creative Commons licence, unless indicated otherwise in a credit line to the material. If material is not included in the article's Creative Commons licence and your intended use is not permitted by statutory regulation or exceeds the permitted use, you will need to obtain permission directly from the copyright holder. To view a copy of this licence, visit http://creativecommons.org/licenses/by/4.0/. 


\section{Background}

Oral biofilm is a highly complex and structured microbial system, and interactions between biofilm microbes are critical to virulence $[1,2]$. Microbial interactions and specific microorganisms are associated with infectious oral diseases such as dental caries and periodontal disease. In particular, a high prevalence of Streptococcus mutans in biofilm is associated with enamel demineralization and dental caries, and Porphyromonas gingivalis plays a key role in progression of gingival and periodontal inflammation by disruption of host tissue homeostasis $[3,4]$.

Previous study reported that orthodontic appliances can change oral microbiota with an increase in oral pathogens , such as cariogenic streptococci and periodontopathic gram-negative bacteria [4]. This may be due to the fact that patients undergoing orthodontic treatments with fixed appliances have difficulty performing proper oral hygiene, which contributes to extensive formation of oral biofilm [5]. Substantial biofilm formation and alteration of oral microbiota associated with fixed orthodontic appliances can induce enamel demineralization and gingival inflammation during orthodontic treatment; prevention of these complications is a continuous challenge faced by orthodontists $[4,6]$.

When bonding orthodontic appliances to the teeth, the enamel surface is subjected to many treatments including acid etching, priming, and application of adhesive to the primed surface. The purpose of these treatments is to change the tooth surface properties to increase the bond strength $[7,8]$. Because surface roughness (SR) and surface wettability (SW) of biomaterials can affect biofilm formation [3, 4, 9-13], the changes in surface properties associated with the orthodontic bonding procedure may significantly influence biofilm development around orthodontic appliances.

Enamel demineralization and gingivitis are the two most common orthodontic complications associated with biofilm formation around orthodontic appliances $[3,6]$. To understand these complications, some studies have analyzed the effects of orthodontic bonding on bacterial adhesion $[3,9$, $12,14]$. However, most studies used a mono-species biofilm model (mainly $S$. mutans) under static conditions [9, 12, 14], which does not simulate the intraoral environment and complex interactions of oral microflora. In addition, few studies have evaluated adhesion and biofilm formation of $P$. gingivalis associated with orthodontic bonding. The purpose of this study was to analyze the effects of changes in SR and SW during orthodontic bonding procedures on biofilm formation and compositional changes in two major oral pathogens, $S$. mutans and $P$. gingivalis, using a multi-species biofilm model with dynamic culture conditions. The null hypothesis was that orthodontic bonding would have no significant effect on biofilm composition.

\section{Methods}

Study sample

Sound bovine incisors were extracted, cleaned, pumiced, and stored in $1 \%$ aqueous solution of chloramine-T (Junsei Chemical, Tokyo, Japan) at $4{ }^{\circ} \mathrm{C}$. After careful preparation to a uniform size $(7.5 \mathrm{~mm}$ diameter and 2.6 $\mathrm{mm}$ thickness), the bovine incisor specimens were randomly divided into three groups according to surface treatment: no surface treatment control (BI), acid-etched surface (ET), and primed surface (PR). The ET specimens were etched with $37 \%$ phosphoric acid gel $(3 \mathrm{M}$, Monrovia, CA, USA) for $20 \mathrm{~s}$, rinsed, and air-dried. In the PR group, Transbond XT primer $(3 \mathrm{M})$ was applied to the etched surface and light-cured for $30 \mathrm{~s}$ using OrthoLuxLED (3 M) after acid etching. For the adhesive specimen group (AD), Transbond XT adhesive (3M) specimens were prepared to the same size as the bovine incisor specimens using a Teflon template. The template was placed on top of a glass slide and filled with Transbond XT adhesive to flush with the top of the plate. The next slide was placed on top of the adhesive and pressed to produce a flat surface of adhesive. They were then light-cured for $20 \mathrm{~s}$ each from the top and bottom according to the manufacturer's instructions. A total of 76 disk-shaped specimens (19 specimens per group) was used in this study: 72 (18 per group) for surface analyses and biofilm formation and 4 (one per group) for scanning electron microscopy (SEM) analysis.

\section{Surface analysis}

To determine surface properties, SR and SW were measured from all 72 specimens prior to the biofilm experiment. After drying, SR of each specimen was evaluated using a confocal laser scanning microscope (LSM 5 Pascal, Carl Zeiss MicroImaging $\mathrm{GmbH}$, Göttingen, Germany) to allow calculation of the arithmetic mean SR from a mean plane in the sampling area $(230 \times 230 \times$ $30 \mu \mathrm{m})$. The measurements were performed at three random points of each disk.

SW was determined by water contact angle, as measured using a sessile drop method with distilled deionized water. Since the degree of wetting increases as contact angle decreases, the contact angle is a useful inverse measurement of SW [15]. A video camera with an image analyzer (Phoenix 300; Surface Electro Optics, Suwon, Korea) visualized the shape of the drop and determined the contact angle. The right and left contact angles of each drop were averaged. All specimens were examined by the same operator.

Surface texture of each specimen was examined using SEM. Each surface was observed under a S-4700 microscope (Hitachi, Tokyo, Japan). Representative images were collected at $\times 500$ and $\times 3000$ magnifications. 


\section{Bacterial preparation}

Because of their major prevalence in oral biofilm and relevance to health, a bacterial consortium of 13 species was used as previously described [16]: Actinobacillus actinomycetemcomitans ATCC 43718, Actinomyces naeslundii KCOM 1472, Fusobacterium nucleatum ATCC 10953, Lactobacillus rhamnosus ATCC 7469, Neisseria subflava ATCC 49275, P. gingivalis KCOM 2797, Prevotella nigrescens ATCC 33563, S. mutans ATCC 700610, Streptococcus oralis ATCC 9811, Streptococcus salivarius CCUG 50207, Streptococcus sanguinis CCUG 17826, Streptococcus sobrinus ATCC 27607, and Veillonella dispar KCOM 1864. Since these species have different optimal growth environments, they were individually grown to midexponential phase according to growth nature (Table 1).

\section{Multi-species biofilm formation}

We cultivated the multi-species biofilm using a CDC biofilm reactor (BioSurface Technologies, Bozeman, MT, USA) with a modified basal mucin medium to provide nutrients and simulate saliva [17]. The medium contained $2.5 \mathrm{~g} / \mathrm{L}$ porcine gastric mucin, $2 \mathrm{~g} / \mathrm{L}$ proteose peptone, $1 \mathrm{~g} /$ $\mathrm{L}$ yeast extract, $1 \mathrm{~g} / \mathrm{L}$ trypticase peptone, $2.5 \mathrm{~g} / \mathrm{L} \mathrm{KCL}, 0.1$ $\mathrm{g} / \mathrm{L}$ cysteine hydrochloride, $0.001 \mathrm{~g} / \mathrm{L}$ hemin, $10 \mathrm{mM}$ urea, and $10 \mathrm{mM}$ glucose. The reactor has a lid supporting eight rods that each held three individual specimens. Three specimens were randomly selected from each of the four groups and inserted into each rod using a Teflon template to expose only the front surface to the culture medium. The equipment, the rods with specimens, and the basal medium mucin were then sterilized. After $3.5 \mathrm{~mL}$ of prepared mixed cell culture ( $1 \%$ of the reactor volume) was injected into the biofilm reactor, modified basal mucin medium was continuously pumped into and flowed out of the reactor at a rate of $100 \mathrm{~mL} / \mathrm{h}$. The reactor was set on a hot stir plate at $37^{\circ} \mathrm{C}$ with a rotational speed of $60 \mathrm{rpm}$ as previously described [18].

\section{Quantitative analysis of bacteria}

The 12 specimens were removed from the biofilm reactor at day 1 (T1) and day 4 (T2). The specimens were transferred into round tubes and washed twice with 1.0 $\mathrm{mL}$ phosphate-buffered saline (PBS; $\mathrm{pH}=7.4$ ) for removing unbound bacteria. Through sonication with three 30-s pulses and 30-s intermittent ice cooling procedures, the biofilm was detached from the specimen surface. The bacterial suspension was then centrifuged at 13,000 rpm for $10 \mathrm{~min}$ and washed with $1.0 \mathrm{~mL}$ PBS.

Bacterial chromosomal DNA was extracted using a CellEase Bacteria II Genomic DNA Extraction Kit (Biocosm, Osaka, Japan). A NanoVue spectrophotometer (General Electric Healthcare Life Sciences, Pittsburgh, PA, USA) was then used to estimate the quality of the isolated DNA. For quantifying $S$. mutans, $P$. gingivalis, and total bacteria in biofilm using real-time polymerase chain reaction (PCR), PCR primers were commercially synthesized from Bioneer (Daejeon, Korea) to amplify the target DNA. The specific primers for $S$. mutans were designed from the $g t f B$ and $g t f U$ genes, and the primers of $P$. gingivalis were based on the $16 \mathrm{~S}$ rRNA gene as previously described [3]. A conserved sequence in the $16 \mathrm{~S}$ rRNA was selected for quantifying total bacteria as previously described [3].

To obtain the standard curve for DNA quantification, DNA was isolated from S. mutans ATCC 700610 and $P$. gingivalis KCOM 2797 and amplified. The amplified products were purified from agarose gels by a QIAquick Gel Extraction Kit (Qiagen, Düsseldorf, Germany), and DNA concentration was determined from absorbance at $260 \mathrm{~nm}$. A 10-fold serial dilution ranging from 10 to $10^{7}$ copies was performed to create DNA standard curves.

Real-time PCR was performed with the Bio-Rad iQ5 system (Bio-Rad, Hercules, CA, USA). The reaction mixtures contained $2 \mu \mathrm{L}$ purified DNA from the specimens, $100 \mathrm{pM}$ primer, and $10 \mu \mathrm{L} 2 \mathrm{x}$ iQ SYBR Green Supermix (Bio-Rad). Distilled water was added to a final volume of $20 \mu \mathrm{L}$. Thermal cycling conditions for quantifying target bacteria are presented in Table 2. Bio-Rad iQ5 Optical System Software was used to analyze all data. The entire quantifying procedure was performed in duplicate and individually repeated five times.

\section{Statistical analysis}

The Kruskal-Wallis test was used to determine differences in SR and water contact angle according to surface treatment. Two-way analysis of variance using the

Table 1 Growth conditions of each bacterial species for the multi-species biofilm model

Bacterial species
Streptococcus mutans, Streptococcus sobrinus, Streptococcus sanguinis,
Streptococcus salivarius, Streptococcus oralis, Actinomyces naeslundii,
Lactobacillus rhamnosus, Veillonella dispar, Neisseria subflava
Fusobacterium nucleatum, Prevotella nigrescens, Porphyromonas
gingivalis

Actinobacillus actinomycetemcomitans

Growth condition

Brain heart infusion medium at $37^{\circ} \mathrm{C}$ with $5 \% \mathrm{CO}_{2}$

Anaerobic condition with tryptic soy agar medium supplemented with $10 \mu \mathrm{g} / \mathrm{mL}$ vitamin $\mathrm{K}, 5 \mu \mathrm{g} / \mathrm{mL}$ hemin, and $5 \%$ sheep blood at $37^{\circ} \mathrm{C}$ for 7 days 
Table 2 Polymerase chain reaction conditions with respect to bacterial species

\begin{tabular}{ll}
\hline Bacterial primer & Cycling condition \\
\hline $\begin{array}{l}\text { Primers for Streptococcus mutans, } \\
\text { Universal primers }\end{array}$ & Initial denaturation for $30 \mathrm{~s}$ at $94^{\circ} \mathrm{C}$ \\
& Forty cycles of denaturation for $20 \mathrm{~s}$ \\
& at $95^{\circ} \mathrm{C}$ \\
& Annealing for $45 \mathrm{~s}$ at $60^{\circ} \mathrm{C}$ \\
& Extension for $10 \mathrm{~s}$ at $60^{\circ} \mathrm{C}$ \\
& Initial denaturation for 1 min at $95^{\circ} \mathrm{C}$ \\
Primers for Porphyromonas & \\
gingivalis & Forty cycles of denaturation for $5 \mathrm{~s}$ at \\
& $95^{\circ} \mathrm{C}$ \\
& Annealing for $15 \mathrm{~s}$ at $61^{\circ} \mathrm{C}$ \\
& Extension for $33 \mathrm{~s}$ at $72^{\circ} \mathrm{C}$ \\
& Final extension for 10 min at $72{ }^{\circ} \mathrm{C}$ \\
\hline
\end{tabular}

Bonferroni correction was used to determine the differences in the levels of bacteria with respect to incubation time and surface type. Spearman rank correlation coefficient test was used to examine the associations between surface properties and bacterial levels at each time point. All values were considered significant at $P<0.05$.

\section{Results}

There was a significant difference in SR among the surface types (Table 3). ET had the roughest surface, while $\mathrm{AD}$ had the smoothest surface. Multiple comparisons showed that the order of SR was $\mathrm{AD}<\mathrm{PR}<\mathrm{BI}<\mathrm{ET}(P$ $<0.05)$, consistent with results from SEM images. BI and ET showed rougher surface textures than PR and AD (Fig. 1). BI had an irregular and uneven appearance due to grooves, ridges, and microfissures (Fig. 1a, e). Because of dissolution of the prism core, ET showed many microporosities throughout the surface (Fig. 1b, f). PR showed a uniformly wrinkled surface and rougher texture (Fig. 1c, g) than AD with minor flaws (Fig. 1d, h).

Significant differences in water contact angle were found among the surface types, but the order of water contact angle tended to be opposite to that of SR, at ET $<\mathrm{PR}<\mathrm{BI}<\mathrm{AD}(P<0.05)$ (Table 3$)$. Because the contact angle is a useful inverse measurement of SW [15], the order of SW can be interpreted as $\mathrm{AD}<\mathrm{BI}<\mathrm{PR}<\mathrm{ET}$.

Table 4 exhibits the differences in bacterial adhesion according to surface type and incubation time. The surface type significantly influenced the adhesion of target bacteria. In all target bacteria, BI and ET demonstrated higher bacterial adhesion than $\mathrm{AD}$, but there was no significant difference in adhesion level between $\mathrm{BI}$ and ET $(\mathrm{AD}<\mathrm{BI}=\mathrm{ET})$. Bacterial adhesion to $\mathrm{PR}$ varied among bacterial species. There was no significant difference in adhesion amount of $S$. mutans between PR and the other three surfaces. Adhesion amount of $P$. gingivalis to $\mathrm{PR}$ was lower than that to ET, but there were no significant differences in adhesion amount of $P$. gingivalis among BI, PR, and AD. Total bacteria exhibited lower adhesion to PR than to BI and ET, but no significant difference in adhesion was found between PR and AD.

There were also significant differences in bacterial adhesion between $\mathrm{T} 1$ and $\mathrm{T} 2$ (Table 4). The adhesion amounts of total bacteria and $S$. mutans increased (T1 < T2, $P<0.05)$, but that of $P$. gingivalis decreased with increased incubation time (T1 $>\mathrm{T} 2, P<0.05)$.

The Spearman rank correlation test demonstrated that the adhesion level of all target bacteria was significantly associated with both SR and water contact angle at each time point (Table 5). Bacterial adhesion was positively correlated with SR, but negatively correlated with water contact angle, irrespective of bacterial species and incubation time. Considering that water contact angle is an inverse measurement of SW [15], these results indicate that both SR and SW are positively correlated with bacterial adhesion.

\section{Discussion}

A common orthodontic bonding procedure includes etching the tooth surface, priming the tooth surface, applying a bracket with a bonding adhesive to the tooth surface, and curing the adhesive between the tooth and bracket. The etched surface provides increased surface area and hydrophilic properties; priming protects the etched enamel surface and enhances the bond with the adhesive [7]; and the bonding adhesive provides adequate physical strength between the bracket base and etched and primed enamel surface, resists displacement by oral function, and transfers requisite orthodontic force to the tooth [8]. Previous in vitro studies have evaluated the relationship between orthodontic bonding and biofilm formation, which is important to prevent common orthodontic complications, such as enamel demineralization and gingival inflammation $[3,5,6,9,12,14]$. However, most studies only used a single bacterial species, mainly $S$.

Table 3 Surface roughness and water contact angle with respect to surface type

\begin{tabular}{lllll}
\hline & $\begin{array}{l}\text { Bovine incisor } \\
(\mathrm{BI})\end{array}$ & $\begin{array}{l}\text { Etching } \\
(\mathrm{ET})\end{array}$ & $\begin{array}{l}\text { Primer } \\
(\mathrm{PR})\end{array}$ & $\begin{array}{l}\text { Multiple } \\
\text { Comparisons }\end{array}$ \\
\hline Surface roughness $(\mu \mathrm{m})$ & $1.61 \pm 0.22$ & $3.50 \pm 0.30$ & $0.32 \pm 0.04$ & $0.11 \pm 0.00$ \\
Water contact angle (degree) & $56.61 \pm 2.50$ & $30.08 \pm 2.94$ & $46.59 \pm 1.51$ & $72.47 \pm 1.62$ \\
\hline
\end{tabular}

The Kruskal-Wallis test was used to determine differences among the four groups and multiple comparisons were performed using the Mann-Whitney tests with the Bonferroni correction at a significant level of $a<0.05$. 

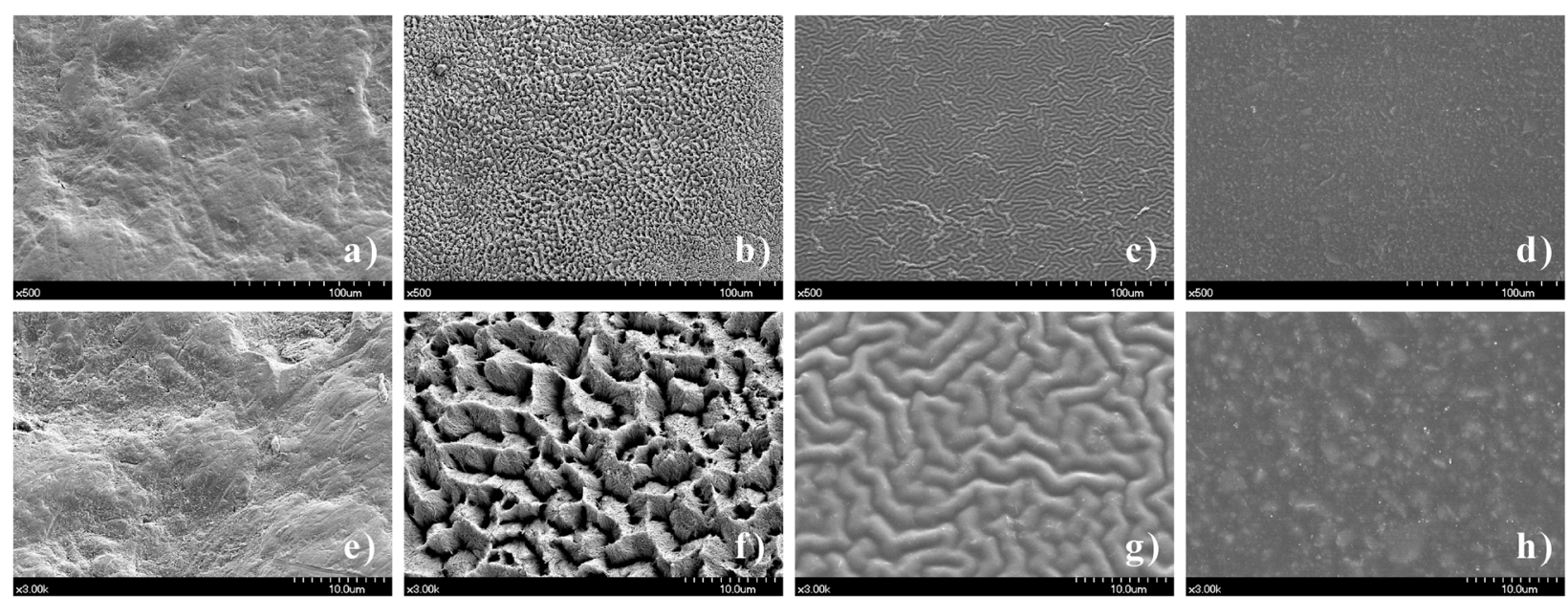

Fig. 1 Scanning electron microscopy images with respect to surface type. a Untreated bovine incisor at $\times 500$ magnification; $\mathbf{b}$ etched bovine incisor at $\times 500$ magnification; c primed bovine incisor at $\times 500$ magnification; $\mathbf{d}$ Transbond XT adhesive at $\times 500$ magnification; e untreated bovine incisor at $\times 3000$ magnification; $\mathbf{f}$ etched bovine incisor at $\times 3000$ magnification; $\mathbf{g}$ primed bovine incisor at $\times 3000$ magnification; $\mathbf{h}$ Transbond XT adhesive at $\times 3000$ magnification

mutans $[9,12,14]$. The single-species method cannot represent interactions of microorganisms associated with oral biofilms. In this study, a multi-species biofilm model was used under dynamic culture conditions to assess the effects of the orthodontic bonding procedure on biofilm formation and compositional changes in two main oral pathogens, S. mutans and P. gingivalis.

Bovine teeth were used to examine the effects of surface properties on biofilm formation in this study because they are the most widely used alternative for

Table 4 Time-related differences in the levels of bacteria with respect to surface type

\begin{tabular}{|c|c|c|c|c|c|}
\hline & \multirow[t]{2}{*}{ Day 1 (T1) } & \multirow[t]{2}{*}{ Day 4 (T2) } & \multicolumn{2}{|l|}{ Significancet } & \multirow{2}{*}{$\begin{array}{l}P \text { value for } \\
\text { interaction }\end{array}$} \\
\hline & & & Treatment & Time & \\
\hline \multicolumn{6}{|c|}{ Streptococcus mutans $\left(\log _{10} / \mathrm{cm}^{2}\right)$} \\
\hline$B l^{a}$ & $4.29 \pm 0.22$ & $5.22 \pm 0.53$ & \multirow[t]{4}{*}{$\mathrm{AD}<\mathrm{BI}=\mathrm{ET}$} & \multirow[t]{4}{*}{$\mathrm{T} 1<\mathrm{T} 2$} & \multirow[t]{4}{*}{0.388} \\
\hline$E T^{\mathrm{b}}$ & $4.47 \pm 0.36$ & $5.31 \pm 0.39$ & & & \\
\hline $\mathrm{PR}^{\mathrm{c}}$ & $4.05 \pm 0.44$ & $5.01 \pm 0.27$ & & & \\
\hline$A D^{d}$ & $3.96 \pm 0.37$ & $4.49 \pm 0.59$ & & & \\
\hline \multicolumn{6}{|c|}{ Porphyromonas gingivalis $\left(\log _{10} / \mathrm{cm}^{2}\right)$} \\
\hline$B 1^{\mathrm{a}}$ & $3.23 \pm 0.31$ & $2.82 \pm 0.30$ & \multirow{4}{*}{$\begin{array}{l}\mathrm{AD}<\mathrm{BI}=\mathrm{ET} \\
\mathrm{PR}<\mathrm{ET}\end{array}$} & \multirow[t]{4}{*}{$\mathrm{T} 1>\mathrm{T} 2$} & \multirow[t]{4}{*}{0.905} \\
\hline$E T^{\mathrm{b}}$ & $3.48 \pm 0.40$ & $3.14 \pm 0.44$ & & & \\
\hline $\mathrm{PR}^{c}$ & $2.80 \pm 0.28$ & $2.52 \pm 0.53$ & & & \\
\hline$A D^{d}$ & $2.57 \pm 0.17$ & $2.36 \pm 0.63$ & & & \\
\hline \multicolumn{6}{|c|}{ Total bacteria $\left(\log _{10} / \mathrm{cm}^{2}\right)$} \\
\hline$B 1^{a}$ & $7.06 \pm 0.34$ & $7.99 \pm 0.24$ & \multirow[t]{4}{*}{$\mathrm{AD}=\mathrm{PR}<\mathrm{BI}=\mathrm{ET}$} & \multirow[t]{4}{*}{$\mathrm{T} 1<\mathrm{T} 2$} & \multirow[t]{4}{*}{0.104} \\
\hline$E T^{\mathrm{b}}$ & $7.25 \pm 0.36$ & $8.11 \pm 0.33$ & & & \\
\hline $\mathrm{PR}^{\mathrm{C}}$ & $6.90 \pm 0.48$ & $7.70 \pm 0.24$ & & & \\
\hline$A D^{d}$ & $6.87 \pm 0.26$ & $7.34 \pm 0.42$ & & & \\
\hline
\end{tabular}

${ }^{\dagger}$ Two-way ANOVA was used to determine significant differences between the two time points using the Bonferroni correction at a significant level of $a<0.05$

antreated bovine incisor

${ }^{\mathrm{b}}$ Etched bovine incisor

cPrimed bovine incisor

${ }^{\mathrm{d}}$ Transbond XT adhesive 
Table 5 Spearman rank correlation coefficients for surface properties and bacterial levels

\begin{tabular}{llll}
\hline Day & Bacteria & Surface roughness $(n=36)$ & Water contact angle $(n=36)$ \\
\hline 1 & Streptococcus mutans & $0.590^{* * *}$ & $-0.456^{* *}$ \\
& Porphyromonas gingivalis & $0.863^{* * *}$ & $-0.635^{* * *}$ \\
& Total bacteria & $0.599^{* * *}$ & $-0.566^{* * *}$ \\
4 & Streptococcus mutans & $0.458^{* *}$ & $-0.351^{* *}$ \\
& Porphyromonas gingivalis & $0.465^{* *}$ & $-0.373^{* *}$ \\
& Total bacteria & $0.844^{* * *}$ & $-0.573^{* * *}$ \\
\end{tabular}

${ }^{* *} P<0.01 ;{ }^{* * *} P<0.001$

human teeth in dental research. They are easy to obtain in good condition and have a relatively large flat surface. Although the physicochemical characteristics of bovine teeth are not identical to those of human teeth [19], many studies have reported that there are no significant differences in micro-morphology, physical properties, and chemical composition [20,21]. In addition, there is no significant difference in biofilm composition between human and bovine teeth [22].

SR and SW are two main surface properties that influence bacterial adhesion and biofilm formation [3, 4, 9-13]. A rough surface provides a favorable environment for bacterial adhesion and biofilm maturation, because a rough surface plays a protective role against shear force and increases the area available for biofilm formation [11, 12]. On the other hand, higher SW facilitates biofilm formation on dental materials $[10,13]$ due to its relation to surface free energy and hydrophilicity [23].

SW is measured by contact angle, which is formed when a droplet of a liquid is placed on a surface [15]. Water is a common liquid to use for measurement of the contact angle because it has no chemical reaction with the underlying surface [24]. We measured the water contact angle of all the specimens to determine the SW prior to starting biofilm experiments, because other probe liquids with different hydrophobicity may affect the surface properties of the underlying material, react with primer or adhesive components, and influence biofilm experiments.

This study demonstrated that surface treatment during orthodontic bonding significantly influences SR and water contact angle. There were significant differences in SR among the surface types (Table 3). The order of $\mathrm{SR}$ was $\mathrm{AD}<\mathrm{PR}<\mathrm{BI}<\mathrm{ET}$, which is partly consistent with the results of a previous study showing that etched hydroxyapatite surface is rougher and adhesive surface is smoother than those of other surfaces [12]. Higher SRs of $\mathrm{BI}$ and ET than PR and AD might be due to the presence of grooves and ridges on bovine enamel and increased surface irregularities by acid etching [25], respectively (Fig. 1). Although the wrinkled surface of PR showed a smoother texture (Fig. 1c, g) than BI and
ET, wrinkle structures may cause PR to be more irregular than $\mathrm{AD}$, resulting in minor flaws (Fig. 1d, h).

There were also significant differences in water contact angle among the four surface types (Table 3). AD exhibited the greatest value followed by BI, PR, and ET (ET < $\mathrm{PR}<\mathrm{BI}<\mathrm{AD})$. Because of the inverse relationship between water contact angle and SW [15], the order of SW may be $\mathrm{AD}<\mathrm{BI}<\mathrm{PR}<\mathrm{ET}$. These findings indicate that both SR and SW have the highest value in ET and the lowest value in AD.

This study demonstrated higher adhesion of $S$. mutans to $\mathrm{BI}$ and ET than to AD (Table 4), which could be explained by the higher SR and SW for BI and ET than for AD (Table 3). Various bacteria are involved in biofilm formation in the oral cavity, which begins with early colonizers, including streptococci and Actinomyces spp., followed by middle-colonizing Porphyromonas spp. and Fusobacteria spp., and late-colonizing Gram-negative anaerobes $[1,2]$. Because $S$. mutans initially adheres to the underlying surface as an early colonizer, adhesion of $S$. mutans may be more significantly affected by surface properties. Previous microscopic examination of biofilms revealed that bacterial adhesion to the enamel surface starts from surface irregularities, such as grooves, perikymata, and cracks [25] (Fig. 1), because rough surfaces can act as a buffer against shear forces, which ease the change from reversible to irreversible bacterial attachment and increase the area available for initial bacterial adhesion. In addition, hydrophilic and wettable surfaces are known to collect more plaque by attracting specific bacteria $[26,27]$. Since hydrophilic bacteria preferentially adhere to a hydrophilic surface [26], hydrophilic oral bacteria, such as S. mutans, easily adhere to the hydrophilic and wettable surface [27]. In this regard, the rougher and wetter surfaces of BI and ET may provide more a favorable surface for adhesion of $S$. mutans than AD.

This study showed that $P$. gingivalis and total bacteria also showed greater adhesion to $\mathrm{BI}$ and ET than to $\mathrm{AD}$ (Table 4). After colonization by early colonizers, a combination of bacterial proliferation and recruitment leads to a bacterial mass increase during biofilm maturation [2]. Therefore, successful adhesion of early colonizers 
such as $S$. mutans leads to sequential co-adhesion and proliferation of middle and late colonizers and results in increase and maturation of the biofilm, which may explain the similar adhesion tendency of $P$. gingivalis and total bacteria to that of $S$. mutans. This hypothesis is supported by the findings of this study demonstrating that SR was positively correlated and water contact angle was negatively correlated with adhesion of $P$. gingivalis and total bacteria as well as $S$. mutans (Table 5). Several studies have also demonstrated that SR has a positive correlation with bacterial adhesion and biofilm formation $[3,11,12]$ and the significant effects of SW on biofilm formation are widely accepted [10, 13]. All these findings suggest that changes in SR and SW during orthodontic bonding procedures may significantly affect bacterial adhesion and biofilm composition.

Biofilm formation can be influenced not only by changes in SR and SW but also by other surface factors during orthodontic bonding procedures. Bacterial adhesion to ET was expected to be higher than to BI, because of its rougher and wetter properties. However, there was no significant difference in adhesion of any bacteria between BI and ET (Table 4). Cytotoxicity of the phosphoric acid used for acid etching may influence bacterial adhesion. A previous study demonstrated that $37 \%$ phosphoric acid has antimicrobial activity by increasing the concentration of hydrogen ions in the microorganism [28]. During the experiment, the remaining phosphoric acid on the irregular surface of the bovine tooth may have influenced the bacterial viability. Although the rougher and wetter surface caused by acid etching could be favorable for bacterial adhesion, the cytotoxic action of phosphoric acid may offset the surface properties. In addition, a previous study reported that an SR over a certain level (over $0.35 \mu \mathrm{m}$ ) might not significantly influence biofilm formation [29]. Although ET was rougher than BI, BI may be rough enough (average $1.61 \mu \mathrm{m}$ of SR, Table 3) to demonstrate no difference in bacterial adhesion.

Bacterial adhesion to PR was different than that to other surfaces. Because PR was rougher and more wettable than AD, but smoother and less wettable than ET (Table 3), bacterial adhesion to PR was expected to be lower than that to ET and higher than that to AD. However, adhesion of the two oral pathogens and total bacteria to PR was not significantly different from that to ET or AD. This result may be due to chemical properties of the primer. The primer is present in a chemically unstable state in the oral environment because of its lower degree of conversion [30]. In particular, bisphenol Aglycidyl methacrylate (bis-GMA), one of the main components of Transbond XT primer, has two opposing characteristics that influence bacterial adhesion and biofilm formation. One is to facilitate biofilm formation of $S$. mutans by increased adhesion capacity, enhanced glucan synthesis, and promotion of sugar transport activity [31]. The other is a toxic effect on oral bacteria, such as inhibiting bacterial growth and decreasing cell viability [31]. The leachable components of the primer with these opposing characteristics may differently influence bacterial adhesion to PR.

This study showed that adhesion of $S$. mutans and total bacteria significantly increased with extended incubation time $(\mathrm{T} 1<\mathrm{T} 2$, Table 4$)$. Since streptococci are facultative anaerobes, they can successfully adhere to the surface and continue to proliferate well in our aerobic culture condition, which led to subsequent maturation of biofilm and eventually resulted in an increase in total bacteria. In contrast to $S$. mutans and total bacteria, the amount of $P$. gingivalis significantly decreased from $\mathrm{T} 1$ to T2 (T1 > T2). $P$. gingivalis is a late colonizer and obligate anaerobe. $P$. gingivalis is sensitive to an oxidative aerobic environment, possibly hindering its growth. These results are consistent with a previous study that examined biofilm formation on orthodontic adhesive under similar culture conditions to our study [3].

This in vitro study showed the lowest bacterial adhesion to $\mathrm{AD}$. In particular, the two main oral pathogens showed less adhesion to AD than to BI and ET. Considering that plaque accumulation and enamel demineralization mainly occur at the interface between tooth and adhesive in clinical practice [32], these findings indicate that when acid etching is wider than intended, covering the etched surface with adhesive may be helpful to reduce biofilm formation around orthodontic appliances. However, it is difficult to maintain a smooth adhesive surface and the remaining adhesive remnant around orthodontic appliances may be difficult to clean properly in the clinical situation. Therefore, clinicians should uniformly apply adhesive, carefully remove adhesive remnants, and perform periodic cleaning around orthodontic appliances to avoid enamel demineralization.

The present study has some limitations. This study showed that there was no significant difference in bacterial adhesion between BI and ET, even though ET had a rougher and more wettable surface than $\mathrm{BI}$. However, the effects of acid etching on bacterial adhesion may be different between human and bovine teeth, because bovine teeth are more irregular and undulating than human teeth [19]. In addition, the multi-species biofilm model used in this study does not simulate the actual oral environment. Further study using an in situ model is needed to evaluate the effects of orthodontic bonding procedures on biofilm formation and to find approaches to minimize the risk of pathologic side effects in orthodontic patients.

\section{Conclusions}

This study demonstrated that surface treatment during orthodontic bonding significantly influences SR and SW. Acid etching significantly increased SR and SW, while 
application of adhesive significantly decreased SR and SW. The changes in SR and SW were significantly associated with biofilm formation and composition. In particular, the two main oral pathogens, S. mutans and $P$. gingivalis, showed greater adhesion to $\mathrm{BI}$ and ET with rougher and more wettable surfaces than to $A D$ with smoother and less wettable surfaces. This in vitro study suggests that changes in surface properties during the orthodontic bonding procedure may be significantly associated with biofilm formation and composition of $S$. mutans and $P$. gingivalis.

\section{Abbreviations}

BI: Untreated bovine enamel surface; ET: Bovine enamel surface etched with 37\% phosphoric acid; PR: Primed enamel surface; AD: Adhesive surface; SW: Surface wettability; SR: Surface roughness

\section{Acknowledgements}

Not applicable

\section{Authors' contributions}

SJ conceived of the study. SJ, BS, and DM contributed to the design and methodological variables. DM and BS performed the experiments. DM, JS, and SJ interpreted the data. SJ, BS, JS, and DM contributed to the writing. SJ, $B S, J S$, and DM read and edited the manuscript. All authors read and approved the final manuscript.

\section{Funding}

This work was supported by the National Research Foundation of Korea [NRF-2017R1A2B4001834].

\section{Availability of data and materials}

The datasets used and/or analyzed during the current study are available from the corresponding author on reasonable request.

\section{Ethics approval and consent to participate}

The ethical approval of this study was waived as mentioned in the manuscript by the Institutional Animal Care and Use Committee.

\section{Consent for publication}

Consent was given by all patients participating in the study.

\section{Competing interests}

The authors declare that they have no competing interests.

\section{Author details}

${ }^{1}$ Department of Orthodontics, School of Dentistry, Seoul National University, 101 Deahak-ro, Jongro-Gu, Seoul 03080, Republic of Korea. ${ }^{2}$ Department of Orthodontics, Seoul National University Dental Hospital, Jongro-Gu, Seoul 03080, Republic of Korea. ${ }^{3}$ Dental Research Institute and Department of Dental Biomaterials, Seoul National University Dental Hospital, Jongro-Gu, Seoul 03080, Republic of Korea. ${ }^{4}$ Dental Research Institute and Department of Orthodontics, Seoul National University School of Dentistry, 101 Daehakro, Jongro-Gu, Seoul 03080, Republic of Korea.

Received: 20 December 2019 Accepted: 28 April 2020

Published online: 01 June 2020

\section{References}

1. Low B, Lee W, Seneviratne CJ, Samaranayake LP, Hagg U. Ultrastructure and morphology of biofilms on thermoplastic orthodontic appliances in 'fast' and 'slow' plaque formers. Eur J Orthod. 2011;33:577-83.

2. Kolenbrander PE, Andersen RN, Blehert DS, Egland PG, Foster JS, Palmer RJ Jr. Communication among oral bacteria. Microbiol Mol Biol Rev. 2002;66: 486-505 table of contents.

3. An JS, Kim K, Cho S, Lim BS, Ahn SJ. Compositional differences in multispecies biofilms formed on various orthodontic adhesives. Eur J Orthod. 2017;39:528-33.
4. Lucchese A, Bondemark L, Marcolina M, Manuelli M. Changes in oral microbiota due to orthodontic appliances: a systematic review. J Oral Microbiol. 2018;10:1476645

5. Metin-Gursoy G, Taner L, Akca G. Nanosilver coated orthodontic brackets: in vivo antibacterial properties and ion release. Eur J Orthod. 2017;39:9-16

6. Migliorati M, Isaia L, Cassaro A, Rivetti A, Silvestrini-Biavati F, Gastaldo L, et al. Efficacy of professional hygiene and prophylaxis on preventing plaque increase in orthodontic patients with multibracket appliances: a systematic review. Eur J Orthod. 2015;37:297-307.

7. Nandhra SS, Littlewood SJ, Houghton N, Luther F, Prabhu J, Munyombwe T, et al. Do we need primer for orthodontic bonding? A randomized controlled trial. Eur J Orthod. 2015;37:147-55.

8. Bearn DR, Aird JC, McCabe JF. Ex vivo bond strength of adhesive precoated metallic and ceramic brackets. Br J Orthod. 1995;22:233-6.

9. Jacobo C, Torrella F, Bravo-Gonzalez LA, Ortiz AJ, Vicente A. In vitro study of the antibacterial properties and microbial colonization susceptibility of four self-etching adhesives used in orthodontics. Eur J Orthod. 2014;36:200-6.

10. Etxeberria M, Lopez-Jimenez L, Merlos A, Escuin T, Vinas M. Bacterial adhesion efficiency on implant abutments: a comparative study. Int Microbiol. 2013;16:235-42.

11. Teughels W, Van Assche N, Sliepen I, Quirynen M. Effect of material characteristics and/or surface topography on biofilm development. Clin Oral Implants Res. 2006;17(Suppl 2):68-81.

12. Yang IH, Lim BS, Park JR, Hyun JY, Ahn SJ. Effect of orthodontic bonding steps on the initial adhesion of mutans streptococci in the presence of saliva. Angle Orthod. 2011;81:326-33.

13. Wassmann $T$, Kreis $S$, Behr M, Buergers $R$. The influence of surface texture and wettability on initial bacterial adhesion on titanium and zirconium oxide dental implants. Int J Implant Dent. 2017;3:32.

14. Ahn SJ, Cho EJ, Oh SS, Lim BS. The effects of orthodontic bonding steps on biofilm formation of Streptococcus mutans in the presence of saliva. Acta Odontol Scand. 2012;70:504-10.

15. Huhtamaki T, Tian X, Korhonen JT, Ras RHA. Surface-wetting characterization using contact-angle measurements. Nat Protoc. 2018;13:1521-38.

16. Bradshaw DJ, Marsh PD, Schilling KM, Cummins D. A modified chemostat system to study the ecology of oral biofilms. J Appl Bacteriol. 1996;80:124-30.

17. Shu M, Browngardt CM, Chen YY, Burne RA. Role of urease enzymes in stability of a 10-species oral biofilm consortium cultivated in a constantdepth film fermenter. Infect Immun. 2003;71:7188-92.

18. Donlan RM, Piede JA, Heyes CD, Sanii L, Murga R, Edmonds P, et al. Model system for growing and quantifying Streptococcus pneumoniae biofilms in situ and in real time. Appl Environ Microbiol. 2004;70:4980-8.

19. Oesterle $L$, Shellhart WC, Belanger GK. The use of bovine enamel in bonding studies. Am J Orthod Dentofacial Orthop. 1998;114:514-9.

20. Camargo MA, Marques MM, de Cara AA. Morphological analysis of human and bovine dentine by scanning electron microscope investigation. Arch Oral Biol. 2008:53:105-8.

21. Tanaka JL, Medici Filho E, Salgado JA, Salgado MA, Moraes LC, Moraes ME, et al. Comparative analysis of human and bovine teeth: radiographic density. Braz Oral Res. 2008;22:346-51.

22. Hara AT, Queiroz CS, Paes Leme AF, Serra MC, Cury JA. Caries progression and inhibition in human and bovine root dentine in situ. Caries Res. 2003; 37:339-44.

23. Song K, Lee J, Choi SO, Kim J. Interaction of surface energy components between solid and liquid on wettability, and its application to textile antiwetting finish. Polymers (Basel). 2019;11.

24. O'Kane C, Oliver RG, Blunden RE. Surface roughness and droplet contact angle measurement of various orthodontic bonding cements. $\mathrm{Br} J$ Orthod. 1993;20:297-305.

25. Wang C, Zhao Y, Zheng S, Xue J, Zhou J, Tang Y, et al. Effect of enamel morphology on nanoscale adhesion forces of streptococcal bacteria : an AFM study. Scanning. 2015;37:313-21.

26. Absolom DR, Lamberti FV, Policova Z, Zingg W, van Oss CJ, Neumann AW Surface thermodynamics of bacterial adhesion. Appl Environ Microbiol. 1983;46:90-7.

27. Arango-Santander S, Pelaez-Vargas A, Freitas SC, Garcia C. A novel approach to create an antibacterial surface using titanium dioxide and a combination of dip-pen nanolithography and soft lithography. Sci Rep. 2018;8:15818.

28. Prado M, Silva EJ, Duque TM, Zaia AA, Ferraz CC, Almeida JF, et al. Antimicrobial and cytotoxic effects of phosphoric acid solution compared to other root canal irrigants. J Appl Oral Sci. 2015;23:158-63. 
29. Park JW, An JS, Lim WH, Lim BS, Ahn SJ. Microbial changes in biofilms on composite resins with different surface roughness: an in vitro study with a multispecies biofilm model. The Journal of Prosthetic Dentistry. 2019;122: 493.e1-.e8.

30. Singh J, Khalichi P, Cvitkovitch DG, Santerre JP. Composite resin degradation products from BisGMA monomer modulate the expression of genes associated with biofilm formation and other virulence factors in Streptococcus mutans. J Biomed Mater Res A. 2009:88:551-60.

31. Kim K, An JS, Lim BS, Ahn SJ. Effect of bisphenol A glycol methacrylate on virulent properties of Streptococcus mutans UA159. Caries Res. 2019;53:84-95.

32. Sukontapatipark W, el-Agroudi MA, Selliseth NJ, Thunold K, Selvig KA. Bacterial colonization associated with fixed orthodontic appliances. A scanning electron microscopy study. Eur J Orthod. 2001;23:475-84.

\section{Publisher's Note}

Springer Nature remains neutral with regard to jurisdictional claims in published maps and institutional affiliations.

\section{Submit your manuscript to a SpringerOpen ${ }^{\circ}$ journal and benefit from:}

- Convenient online submission

- Rigorous peer review

- Open access: articles freely available online

- High visibility within the field

- Retaining the copyright to your article

Submit your next manuscript at $\boldsymbol{\nabla}$ springeropen.com 